\title{
Dynamic and Static Characteristics of Wavy Annular Seals in Turbulent Flow
}

\author{
Satyam Shivam Gautam ${ }^{1)}$ and Mihir Kumar Ghosh ${ }^{2)^{*}}$ \\ ${ }^{1)}$ Mechanical Engineering Department, North Eastern Regional Institute of Science and Technology \\ Itanagar, Arunachal Pradesh - 791 109, India \\ ${ }^{2)}$ Mechanical Engineering Department, Institute of Technology, Banaras Hindu University \\ Varanasi - 221005 , India \\ *Corresponding author: mkghosh47@gmail.com
}

( Manuscript received 14 May 2009; accepted 26 October 2009; published 15 January 2010 )

\begin{abstract}
This paper presents results of a theoretical analysis to determine the leakage flow and dynamic characteristics of circumferential wave geometry annular seals using turbulent lubrication theory. Turbulent lubrication equations based on an eddy viscosity model have been used to develop the turbulent Reynolds equation. Convective fluid inertia effects have been incorporated using the perturbation approach in turbulent lubrication. To determine the dynamic characteristics i.e. stiffness, damping and whirl ratio, perturbation theory for small amplitude vibration of the journal center has been adopted. In general, it has been found that circumferential wave geometry improves the performance of the annular seal at higher speeds and increases in the $\mathrm{L} / \mathrm{D}$ and taper ratios.
\end{abstract}

Keywords: wave seal, turbulent lubrication, leakage flow, rotor dynamic behavior, whirl ratio

\section{Introduction}

Multi-lobe and wave journal bearings have been the subject of several investigations to ascertain their suitability to improve stability of fluid film bearings. Turbulent flow conditions are often observed in high-speed bearings and seals that use low viscosity fluids such as water or process fluids. Therefore, theoretical models to address technical issues related to turbulence in the fluid film have been developed. Turbulence is generally characterized by increased shear stress. Theoretical models developed to include turbulence in fluid film lubrication use either mixing length or the law of wall and eddy diffusivity concepts. Most widely used theories of turbulent lubrication are those of $\mathrm{Ng}$ and $\mathrm{Pan}^{1)}$ and Elrod and $\mathrm{Ng}^{2)}$ which are based on law of wall and the eddy diffusivity concept and bulk flow theory of Hirs ${ }^{3)}$. It is known that these theories lead to almost identical results at high Reynolds numbers. Discrepancies occur only in transition flow regions. Black ${ }^{4)}$ determined expressions for the effective viscosity in journal bearings with high axial flows in turbulent lubrication based on rotational and axial flow Reynolds numbers of screw flow.

Turbulence in seals has been subject of various investigations in the past several decades. Child $^{\text {5) }}$ presented theoretical analysis of turbulent lubrication of annular seals using bulk flow theory of Hirs. Childs and Dressman $^{6}$ and Lindsay et al. ${ }^{7)}$ analyzed the convergent-divergent axial taper on the dynamic performance of an annular seal. However, ample literature which deals with analysis and performance of annular seals exist and it is not possible to include all details in a short review. The influence of circumferential geometry variation on the performance of the annular seals has not been studied properly as yet. Contrary to this adequate literature is found which report on the effect of circumferential geometry variation on the static and dynamic performance of fluid film journal bearings.

It is well known that multi-lobe geometry improves the dynamic performance of the journal bearings. Soni et al. ${ }^{8)}$ studied the performance of two lobe journal bearing using turbulent lubrication theory of $\mathrm{Ng}$ and $\mathrm{Pan}$ 1). Vaidyanathan and Keith ${ }^{9)}$ analyzed elliptical and two lobe journal bearings. $\mathrm{Li}$ et al. ${ }^{10)}$ investigated on the stability and transient characteristics of four multi-lobe journal bearing configurations. Abdul Wahed et al. ${ }^{11)}$ discussed the stability and unbalance response of multi-lobe journal bearings. Effect of surface waviness on the load carrying capacity of plain slider bearings was investigated by Hargreaves ${ }^{12)}$ and Hassan ${ }^{13)}$.

The concept of a waved journal bearing was developed by Dimofte for high performance 
turbomachinery applications ${ }^{14)}$. A wave journal bearing design is relatively simple as compared to other noncircular geometries. The wave journal bearing unlike plain circular journal bearing can be represented by a waved bush or sleeve wrapped around the shaft. Its performance in comparison to circular and other noncircular bearings was later investigated by Dimofte ${ }^{15,16)}$ in compressible lubrication and it was shown that wave geometry improves static and dynamic performance. Experimental investigation by Lambrulescu et al. ${ }^{17)}$ also lends credibility to the findings of Dimofte. Further investigation on wave bearings for heavily loaded applications and dynamic stability regime was carried out by Dimofte et al. ${ }^{18)}$ and Ene et al. ${ }^{19)}$ respectively. Matsuda et al. ${ }^{20)}$ attempted to determine an optimized clearance configuration for journal bearings to enhance the stability of the bearing. The optimized configuration is similar to two wave geometry. A theoretical approach based on theory presented by Reinhardt and Lund ${ }^{21)}$ for laminar films to include fluid inertia was adopted by the authors ${ }^{22}$ to investigate the static and dynamic performance of an annular seal in turbulent flow.

In the present investigation improvement over the theory presented earlier by the authors ${ }^{22)}$ has been done to investigate the dynamic and static performance of circumferential wavy annular seals in turbulent flow regime. The basic difference lie in the inclusion of the fluid inertia effect in the development of Reynolds' equation in turbulent flow. In the previous paper fluid inertia was estimated using the equations of steady state flow velocities based on laminar flow theory. However, in the present theory steady state flow velocities have been estimated using equations based on turbulent flow neglecting fluid inertia terms. This leads to a modified Reynolds' equation which has been used for further analysis. Seal leakage flow, stiffness, damping and whirl ratio for stability have been determined using the analytical procedure described in the theoretical analysis section. The performance of an annular wavy seal has been compared with the performance of a circular seal. It has been observed that a wavy seal can improve the characteristics of an annular seal.

\section{Theoretical Analysis and film thicknesses}

The film thickness expressions for parallel and tapered circumferential wave seals, as shown in Figs. 1 and 2, are expressed respectively as:

$$
\begin{aligned}
& \bar{h}=\frac{h}{C}=1.0+\varepsilon \cos \theta+\varepsilon_{\omega} \cos \left[n_{c w}\left(\theta+\alpha_{1}\right)\right] \\
& \bar{h}=\frac{h}{C}=1.0+\varepsilon \cos \theta+\varepsilon_{\omega} \cos \left[n_{c w}\left(\theta+\alpha_{1}\right)\right]+z \frac{\Delta C}{C}
\end{aligned}
$$

where, $\Delta C=\left(C_{i}-C\right) / L$

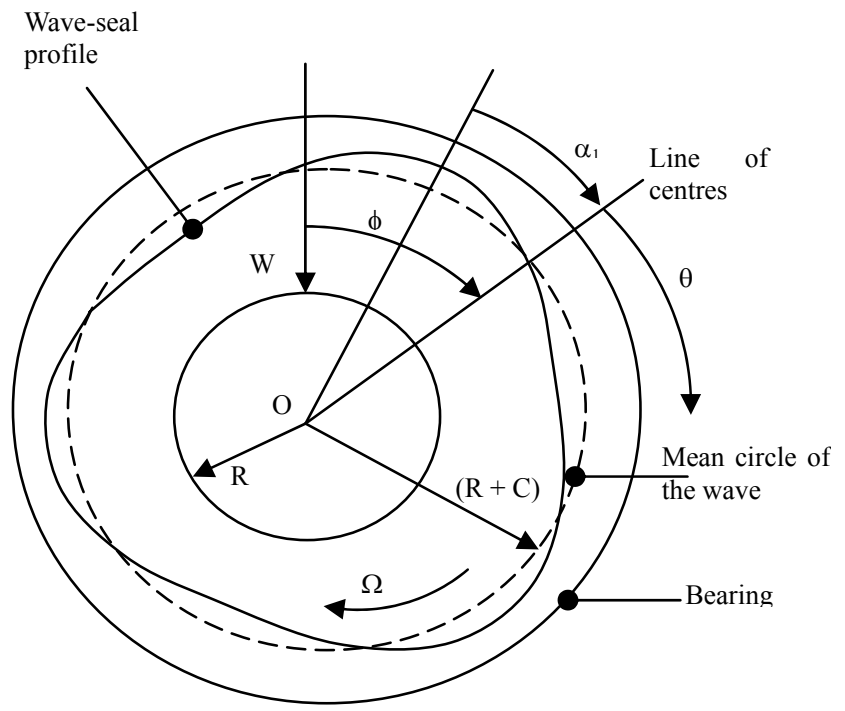

Fig. 1 Circumferential wave annular seal

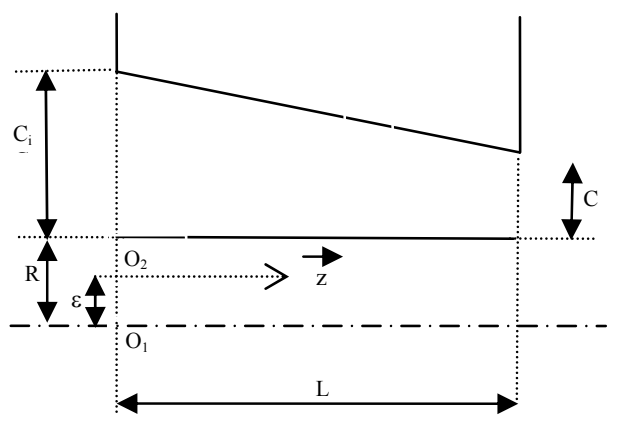

Fig. 2 Tapered seal geometry

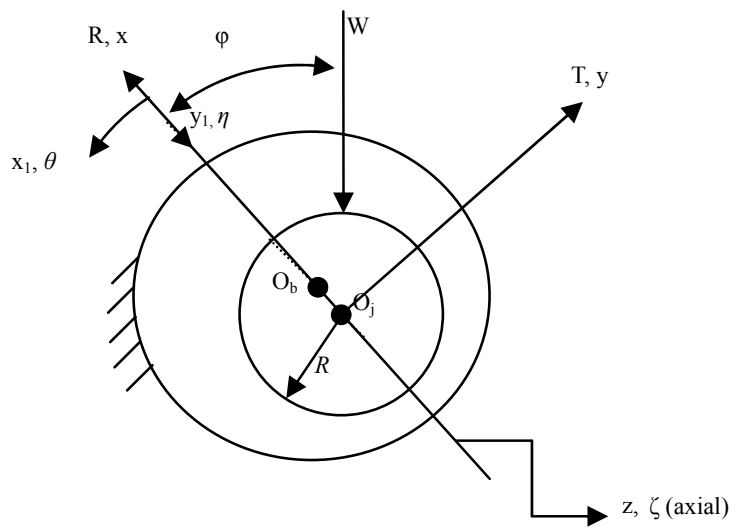

Fig. 3 Circular annular seal coordinates

\subsection{Derivation of governing equations}

The governing differential equations for the turbulent flow of an incompressible lubricant in the clearance space of a seal including fluid inertia effects is written in the dimensionless form using the coordinate systems given in Fig. 3. 
Momentum Equations:

$$
\begin{aligned}
\lambda_{t}\left\{\frac{\partial \bar{u}}{\partial \tau}+\bar{u} \frac{\partial \bar{u}}{\partial \theta}+\bar{v} \frac{\partial \bar{u}}{\partial \eta}+\bar{w} \frac{\partial \bar{u}}{\partial \zeta}\right\} & =-\frac{1}{\left(1+\varepsilon^{\prime} / v\right)} \frac{\partial \bar{p}}{\partial \theta}+\frac{\partial^{2} \bar{u}}{\partial \eta^{2}} \\
0 & =-\frac{\partial \bar{p}}{\partial \eta} \\
\lambda_{t}\left\{\frac{\partial \bar{w}}{\partial \tau}+\bar{u} \frac{\partial \bar{w}}{\partial \theta}+\bar{v} \frac{\partial \bar{w}}{\partial \eta}+\bar{w} \frac{\partial \bar{w}}{\partial \zeta}\right\} & =-\frac{1}{\left(1+\varepsilon^{\prime} / v\right)} \frac{\partial \bar{p}}{\partial \zeta}+\frac{\partial^{2} \bar{w}}{\partial \eta^{2}}
\end{aligned}
$$

Continuity Equations:

$$
\frac{\partial \bar{u}}{\partial \theta}+\frac{\partial \bar{v}}{\partial \eta}+\frac{\partial \bar{w}}{\partial \zeta}=0
$$

where, $\theta=\frac{x_{1}}{R}, \zeta=\frac{z}{R}, \eta=\frac{y_{1}}{C}, \bar{u}=\frac{u}{R \Omega}$,

$$
\bar{v}=\frac{v}{C \Omega}, \quad \bar{w}=\frac{w}{R \Omega}, \quad \bar{p}=\frac{p}{\Lambda p_{a}}, \quad \bar{h}=\frac{h}{C}, \quad \tau=\omega t
$$

The velocity boundary conditions at the seal and journal surfaces are given as:

$$
\left\{\begin{array}{l}
\eta=0: \quad \bar{u}=\bar{v}=\bar{w} \equiv 0, \text { at seal surface } \\
\eta=\bar{h}, \bar{u}=1, \bar{w}=0, \bar{v}=\frac{\partial \bar{h}}{\partial \theta}+\frac{\partial \bar{h}}{\partial \tau} \text {, at journal surface(5) }
\end{array}\right.
$$

At moderate values of the Reynolds number, however, the influence of inertia terms may become noticeable. A procedure was developed by Reinhardt and Lund ${ }^{21)}$ to investigate the effect of fluid inertia in laminar flow through perturbation method which has been adopted here to include fluid inertia effect in turbulent flow regime. Thus, film pressure and fluid velocities are perturbed to obtain linear equations as:

$$
\left\{\begin{array}{l}
\bar{p}=\bar{p}_{0}+\lambda_{t} \bar{p}_{1}+0\left(\lambda_{t}^{2}\right) \\
\bar{u}=\bar{u}_{0}+\lambda_{t} \bar{u}_{1}+0\left(\lambda_{t}^{2}\right)
\end{array}\right.
$$

and analogously for $\bar{v}$ and $\bar{w}$.

The perturbation parameter ' $\lambda_{t}$ ' is the film Reynolds number in turbulent flow and is required to account for the inertia forces:

$$
\lambda_{t}=(C / R) R_{c}^{*}
$$

where, turbulent Reynolds number: $R_{c}^{*}=\rho C R \Omega / \mu^{*}$ and $\mu^{*}=\mu\left(1+\varepsilon^{\prime} / v\right)$

$\mu^{*}$ is the effective viscosity in turbulent flow.

Higher order terms can be neglected in comparison to first order terms when perturbation parameter is small i.e. $\lambda_{t}<<1$.

Substituting equation (6) into equations (1-4) and collecting terms of like order in $\lambda_{t}$ one would obtain zeroeth order and first order equations. Integration of zeroeth order momentum equations would yield flow velocities when fluid inertia is neglected as follows:

$$
\left\{\begin{aligned}
\bar{u}_{0} & =-\frac{1}{2} \frac{\partial \bar{p}_{0}}{\partial \theta} \frac{\eta(\bar{h}-\eta)}{\left(1+\varepsilon^{\prime} / v\right)}+\frac{\eta}{\bar{h}} \\
\bar{w}_{0} & =-\frac{1}{2} \frac{\partial \bar{p}_{0}}{\partial \zeta} \frac{\eta(\bar{h}-\eta)}{\left(1+\varepsilon^{\prime} / v\right)} \\
\bar{v}_{0}= & {\left[\frac{\eta^{2}(2 \bar{h}-\eta)}{\bar{h}^{3}}\right] \frac{\partial \bar{h}}{\partial \theta}+\left[\frac{\eta^{2}(3 \bar{h}-2 \eta)}{\bar{h}^{3}}\right] \frac{\partial \bar{h}}{\partial \tau} } \\
& -\left[\frac{\eta^{2}(\bar{h}-\eta)}{2 \bar{h}\left(1+\varepsilon^{\prime} / v\right)}\right]\left[\frac{\partial \bar{p}_{0}}{\partial \theta} \frac{\partial \bar{h}}{\partial \theta}+\frac{\partial \bar{p}_{0}}{\partial \zeta} \frac{\partial \bar{h}}{\partial \zeta}\right]
\end{aligned}\right.
$$

Thus, Reynolds equation neglecting fluid inertia effects as developed by $\mathrm{Ng}$, Pan and Elrod ${ }^{1,2)}$ is obtained by substituting the above expressions in continuity equation as:

$$
\frac{\partial}{\partial \theta}\left(\frac{\bar{h}^{3}}{K_{\theta}} \frac{\partial \bar{p}_{0}}{\partial \theta}\right)+\frac{\partial}{\partial \zeta}\left(\frac{\bar{h}^{3}}{K_{\zeta}} \frac{\partial \bar{p}_{0}}{\partial \zeta}\right)=\frac{1}{2} \frac{\partial \bar{h}}{\partial \theta}+\frac{\partial \bar{h}}{\partial \tau}
$$

Integration of first order momentum equations would yield perturbed flow velocities respectively. Using respective boundary conditions and flow continuity equation one can determine turbulent Reynolds equations including fluid inertia effects as:

$$
\begin{aligned}
& \frac{\partial}{\partial \theta}\left\{\frac{\bar{h}^{3}}{K_{\theta}} \frac{\partial \bar{p}_{1}}{\partial \theta}\right\}+\frac{\partial}{\partial \zeta}\left\{\frac{\bar{h}^{3}}{K_{\zeta}} \frac{\partial \bar{p}_{1}}{\partial \zeta}\right\}=\frac{\partial}{\partial \theta}\left\{-\frac{\bar{h}^{7}}{2240} \frac{1}{K_{\theta}^{2}} \frac{\partial}{\partial \theta}\left\{\left(\frac{\partial \bar{p}_{0}}{\partial \theta}\right)^{2}+\left(\frac{\partial \bar{p}_{0}}{\partial \zeta}\right)^{2}\right\}\right. \\
& \frac{\bar{h}^{6}}{560} \frac{1}{K_{\theta}^{2}} \frac{\partial \bar{h}}{\partial \theta}\left(\frac{\partial \bar{p}_{0}}{\partial \theta}\right)^{2}+\frac{\bar{h}^{5}}{240} \frac{1}{K_{\theta}} \frac{\partial^{2} \bar{p}_{0}}{\partial \theta^{2}}+\frac{13 \bar{h}^{4}}{1680} \frac{1}{K_{\theta}} \frac{\partial \bar{h}}{\partial \theta} \frac{\partial \bar{p}_{0}}{\partial \theta} \\
& \left.-\frac{\bar{h}^{2}}{120} \frac{\partial \bar{h}}{\partial \theta}-\frac{\bar{h}^{6}}{560} \frac{1}{K_{\theta}^{2}} \frac{\partial \zeta}{\partial \zeta} \frac{\partial \bar{p}_{0}}{\partial \theta} \frac{\partial \bar{p}_{0}}{\partial \zeta}+\frac{13 \bar{h}^{4}}{840} \frac{1}{K_{\theta}} \frac{\partial \bar{p}_{0}}{\partial \theta} \frac{\partial \bar{h}}{\partial \tau}\right\}+
\end{aligned}
$$$$
\frac{\partial}{\partial \zeta}\left\{-\frac{\bar{h}^{7}}{2240} \frac{1}{K_{\zeta}^{2}} \frac{\partial}{\partial \zeta}\left\{\left(\frac{\partial \bar{p}_{0}}{\partial \theta}\right)^{2}+\left(\frac{\partial \bar{p}_{0}}{\partial \zeta}\right)^{2}\right\}-\frac{\bar{h}^{6}}{560} \frac{1}{K_{\zeta}^{2}} \frac{\partial \bar{h}}{\partial \theta} \frac{\partial \bar{p}_{0}}{\partial \theta} \frac{\partial \bar{p}_{0}}{\partial \zeta}+\right.
$$$$
\frac{\bar{h}^{5}}{240} \frac{1}{K_{\zeta}} \frac{\partial^{2} \bar{p}_{0}}{\partial \theta \partial \zeta}+\frac{13 \bar{h}^{4}}{1680} \frac{1}{K_{\zeta}} \frac{\partial \bar{h}}{\partial \theta} \frac{\partial \bar{p}_{0}}{\partial \zeta}-\frac{\bar{h}^{6}}{560} \frac{1}{K_{\zeta}^{2}} \frac{\partial \bar{h}}{\partial \zeta}\left(\frac{\partial \bar{p}_{0}}{\partial \zeta}\right)^{2}+
$$

$$
\left.\frac{13 \bar{h}^{4}}{840} \frac{1}{K_{\zeta}} \frac{\partial \bar{p}_{0}}{\partial \zeta} \frac{\partial \bar{h}}{\partial \tau}\right\}
$$

Since $\bar{p}_{0}$ is the steady state turbulent film pressure without fluid inertia effect, the dynamic terms viz. $\frac{\partial^{2} \bar{p}_{0}}{\partial \theta \partial \tau}$ and $\frac{\partial^{2} \bar{p}_{0}}{\partial \zeta \partial \tau}$ can be neglected.

Launder and Leschziner ${ }^{23)}$ pointed out that in the presence of inertia, the wall shear stresses are not uniquely related to pressure gradients, rather, they are uniquely related to the mean velocities if the shape of profiles does not change with inertia. Perturbation 
approach also assumes that inertia effects are not very large and therefore does not influence the shape of velocity profiles. Therefore in the present investigation, it is assumed that eddy diffusivity is dominated by couette shear and turbulent model of Hirs ${ }^{3)}$ is used in the present analysis.

$$
K_{\theta}=0.0687 R_{c}^{0.75} \quad, \quad K_{\zeta}=0.0392 R_{c}^{0.75} \quad \text { for }
$$

$10^{3}<R_{c}<1 \times 10^{5}$

In this $\bar{p}_{0}$ is the steady state lubricant film pressure in turbulent flow when fluid inertia is neglected and is to be determined by solving equation (8) satisfying appropriate boundary conditions neglecting time dependant squeeze term.

For the journal center executing small amplitude vibrations around an equilibrium position, first order perturbation equations for pressure, film thickness and turbulent coefficients can be used to develop perturbed Reynolds equations (zeroeth and first order equations). Thus, pressure, film thickness and turbulent co-efficient can be written as:

$$
\left\{\begin{array}{l}
\bar{p}_{1}=\bar{p}_{10}+\varepsilon_{1} e^{i \tau} \bar{p}_{11}+\varepsilon_{0} \varphi_{1} e^{i \tau} \bar{p}_{12} \\
\bar{h}=\bar{h}_{0}+\varepsilon_{1} e^{i \tau} \cos \theta+\varepsilon_{0} \varphi_{1} e^{i \tau} \sin \theta \\
K_{\theta}=K_{\theta_{0}}+\varepsilon_{1} e^{i \tau} K_{\theta_{1}}+\varepsilon_{0} \varphi_{1} e^{i \tau} K_{\theta_{2}} \\
K_{\zeta}=K_{\zeta_{0}}+\varepsilon_{1} e^{i \tau} K_{\zeta_{1}}+\varepsilon_{0} \varphi_{1} e^{i \tau} K_{\zeta_{2}}
\end{array}\right.
$$

where, $K_{\theta_{1}}=\frac{\partial K_{\theta}}{\partial \theta}, K_{\theta_{2}}=\frac{\partial K_{\theta}}{\partial \zeta}, K_{\zeta_{1}}=\frac{\partial K_{\zeta}}{\partial \theta}, \quad K_{\zeta_{2}}=\frac{\partial K_{\zeta}}{\partial \zeta}$ and $\bar{h}_{0}=1+\varepsilon_{0} \cos \theta$

Substituting equations (10) in equation (9) zeroeth and first order equations are obtained as:

Zeroeth-order dimensionless equation

$\frac{\partial}{\partial \theta}\left\{\frac{\bar{h}_{0}^{3}}{K_{\theta_{0}}} \frac{\partial \bar{p}_{10}}{\partial \theta}\right\}+\frac{\partial}{\partial \zeta}\left\{\frac{\bar{h}_{0}^{3}}{K_{\zeta_{0}}} \frac{\partial \bar{p}_{10}}{\partial \zeta}\right\}=\frac{\partial}{\partial \theta}\left\{-\frac{\bar{h}_{0}^{7}}{2240} \frac{1}{K_{\theta_{0}}^{2}} \frac{\partial}{\partial \theta}\left\{\left(\frac{\partial \bar{p}_{0}}{\partial \theta}\right)^{2}+\left(\frac{\partial \bar{p}_{0}}{\partial \zeta}\right)^{2}\right\}\right.$

$-\frac{\bar{h}_{0}^{6}}{560} \frac{1}{K_{\theta_{0}}{ }^{2}} \frac{\partial \bar{h}_{0}}{\partial \theta}\left(\frac{\partial \bar{p}_{0}}{\partial \theta}\right)^{2}+\frac{\bar{h}_{0}^{5}}{240} \frac{1}{K_{\theta_{0}}} \frac{\partial^{2} \bar{p}_{0}}{\partial \theta^{2}}+\frac{13 \bar{h}_{0}^{4}}{1680} \frac{1}{K_{\theta_{0}}} \frac{\partial \bar{h}_{0}}{\partial \theta} \frac{\partial \bar{p}_{0}}{\partial \theta}-$

$\left.\frac{\bar{h}_{0}^{2}}{120} \frac{\partial \bar{h}_{0}}{\partial \theta}-\frac{\bar{h}_{0}^{6}}{560} \frac{1}{K_{0}^{2}} \frac{\partial \bar{h}_{0}}{\partial \zeta} \frac{\partial \bar{p}_{0}}{\partial \theta} \frac{\partial \bar{p}_{0}}{\partial \zeta}+\frac{13 \bar{h}_{0}^{4}}{840} \frac{1}{K_{0}} \frac{\partial \bar{p}_{0}}{\partial \theta} \frac{\partial \bar{h}_{0}}{\partial \tau}\right\}+$

$\frac{\partial}{\partial \zeta}\left\{-\frac{\bar{h}_{0}}{2240} \frac{1}{K_{\zeta_{0}}{ }^{2}} \frac{\partial}{\partial \zeta}\left\{\left(\frac{\partial \bar{p}_{0}}{\partial \theta}\right)^{2}+\left(\frac{\partial \bar{p}_{0}}{\partial \zeta}\right)^{2}\right\}-\frac{\bar{h}_{0}}{560} \frac{1}{K_{\zeta_{0}}{ }^{2}} \frac{\partial \bar{h}_{0}}{\partial \theta} \frac{\partial \bar{p}_{0}}{\partial \theta} \frac{\partial \bar{p}_{0}}{\partial \zeta}+\right.$

$\frac{\bar{h}_{0}^{5}}{240} \frac{1}{K_{\zeta_{0}}} \frac{\partial^{2} \bar{p}_{0}}{\partial \theta \partial \zeta}+\frac{13 \bar{h}_{0}^{4}}{1680} \frac{1}{K_{\zeta_{0}}} \frac{\partial \bar{h}_{0}}{\partial \theta} \frac{\partial \bar{p}_{0}}{\partial \zeta}-\frac{\bar{h}_{0}^{6}}{560} \frac{1}{K_{\zeta_{0}}{ }^{2}} \frac{\partial \bar{h}_{0}}{\partial \zeta}\left(\frac{\partial \bar{p}_{0}}{\partial \zeta}\right)^{2}+$

$\left.\frac{13 \bar{h}_{0}^{4}}{840} \frac{1}{K_{\zeta_{0}}} \frac{\partial \bar{p}_{0}}{\partial \zeta} \frac{\partial \overline{h_{0}}}{\partial \tau}\right\}$

\section{First-order dimensionless equations}

First order perturbed dynamic Reynolds equations for determining dynamic pressures $p_{11}$ and $p_{12}$ is written as:

$\frac{\partial}{\partial \theta}\left\{\frac{\bar{h}_{0}{ }^{3}}{K_{\theta_{0}}} \frac{\partial \bar{p}_{1 j}}{\partial \theta}+\frac{3 \bar{h}_{0}^{2} h_{j}}{K_{\theta_{0}}} \frac{\partial \bar{p}_{10}}{\partial \theta}-\frac{K_{\theta_{j}} \bar{h}_{0}^{3}}{K_{\theta_{0}}^{2}} \frac{\partial \bar{p}_{10}}{\partial \theta}\right\}+\frac{\partial}{\partial \zeta}\left\{\frac{\bar{h}_{0}{ }^{3}}{K_{\zeta_{0}}} \frac{\partial \bar{p}_{1 j}}{\partial \zeta}\right.$

$\left.+\frac{3 h_{0}^{2} h_{j}}{K_{\zeta_{0}}} \frac{{\overline{p_{10}}}_{10}}{\partial \zeta}-\frac{K_{\zeta_{j}} \bar{h}_{0}^{-3}}{K_{\zeta_{0}}^{2}} \frac{\bar{p}_{10}}{\partial \zeta}\right\}=\frac{\partial}{\partial \theta}\left\{-\frac{1}{224}\left(\frac{7 h_{0} h_{j}}{K_{\theta_{0}}^{2}}-\frac{\overline{2} \bar{h}_{0}^{7} K_{\theta_{j}}}{K_{\theta_{0}}^{3}}\right) \frac{\partial}{\partial \theta}\left\{\left(\frac{{\widetilde{p_{0}}}_{0}}{\partial \theta}\right)^{2}+\left(\frac{\widetilde{\Phi}_{0}}{\partial \zeta}\right)^{2}\right\}\right.$

$\frac{1}{560}\left(\frac{6 \bar{h}_{0}^{5} h_{j}}{K_{\theta_{0}}^{2}} \frac{\partial \bar{h}_{0}}{\partial \theta}-\frac{2 \bar{h}_{0}^{6} K_{\theta_{j}}}{K_{\theta_{0}}^{3}} \frac{\partial \bar{h}_{0}}{\partial \theta}+\frac{\bar{h}_{0}^{6}}{K_{\theta_{0}}^{2}} \frac{\partial \bar{h}_{j}}{\partial \theta}\right)\left(\frac{\partial \bar{p}_{0}}{\partial \theta}\right)^{2}+$

$\frac{1}{240}\left(\frac{5 \bar{h}_{0}^{4} h_{j}}{K_{\theta_{0}}}-\frac{\bar{h}_{0}^{5} K_{\theta_{j}}}{K_{\theta_{0}}^{2}}\right) \frac{\partial^{2} \bar{p}_{0}}{\partial \theta^{2}}+\frac{13}{1680}\left(\frac{4 \bar{h}_{0}^{3} h_{j}}{K_{\theta_{0}}} \frac{\partial \bar{h}_{0}}{\partial \theta}-\frac{\bar{h}_{0}^{4} K_{\theta_{j}}}{K_{\theta_{0}}^{2}} \frac{\partial \bar{h}_{0}}{\partial \theta}+\right.$

$\left.+\frac{\bar{h}_{0}^{4}}{K_{\theta_{0}}} \frac{\partial \bar{h}_{j}}{\partial \theta}\right)\left(\frac{\partial \bar{p}_{0}}{\partial \theta}\right)-\left(\frac{\bar{h}_{0} \bar{h}_{j}}{60} \frac{\partial \bar{h}_{0}}{\partial \theta}+\frac{\bar{h}_{0}^{2}}{120} \frac{\partial \bar{h}_{j}}{\partial \theta}\right)$

$-\frac{1}{560}\left(\frac{6 \bar{h}_{0}^{5} h_{j}}{K_{\theta_{0}}^{2}} \frac{\partial \bar{h}_{0}}{\partial \zeta}-\frac{2 \bar{h}_{0}^{6} K_{\theta_{j}}}{K_{\theta_{0}}^{3}} \frac{\partial \bar{h}_{0}}{\partial \zeta}+\frac{\bar{h}_{0}^{6}}{K_{\theta_{0}}^{2}} \frac{\partial \bar{h}_{j}}{\partial \zeta}\right)\left(\frac{\partial \bar{p}_{0}}{\partial \theta}\right)\left(\frac{\partial \bar{p}_{0}}{\partial \zeta}\right)$

$+\frac{13}{840}\left(\frac{4 \bar{h}_{0}^{3} h_{j}}{K_{\theta_{0}}} \frac{\partial \bar{h}_{0}}{\partial \tau}-\frac{\bar{h}_{0}^{4} K_{\theta_{j}}}{K_{\theta_{0}}^{2}} \frac{\partial \bar{h}_{0}}{\partial \tau}+i \frac{\bar{h}_{0}^{4} \bar{h}_{j}}{K_{\theta_{0}}}\right)\left(\frac{\partial \bar{p}_{0}}{\partial \theta}\right)+$

$\frac{\partial}{\partial \zeta}\left\{-\frac{1}{2240}\left(\frac{7 \bar{h}_{0}^{6} h_{j}}{K_{\zeta_{0}}^{2}}-\frac{2 \bar{h}_{0}^{7} K_{\zeta_{j}}}{K_{\zeta_{0}}^{3}}\right) \frac{\partial}{\partial \zeta}\left\{\left(\frac{\partial \bar{p}_{0}}{\partial \theta}\right)^{2}+\left(\frac{\partial \bar{p}_{0}}{\partial \zeta}\right)^{2}\right\}-\right.$

$\frac{1}{560}\left(\frac{6 \bar{h}_{0}^{5} h_{j}}{K_{\zeta_{0}}^{2}} \frac{\partial \bar{h}_{0}}{\partial \theta}-\frac{2 \bar{h}_{0}^{6} K_{\zeta_{j}}}{K_{\zeta_{0}}^{3}} \frac{\partial \bar{h}_{0}}{\partial \theta}+\frac{\bar{h}_{0}^{6}}{K_{\zeta_{0}}^{2}} \frac{\partial \bar{h}_{j}}{\partial \theta}\right)\left(\frac{\partial \bar{p}_{0}}{\partial \theta}\right)\left(\frac{\partial \bar{p}_{0}}{\partial \zeta}\right)$

$+\frac{1}{240}\left(\frac{5 \bar{h}_{0}^{4} h_{j}}{K_{\zeta_{0}}}-\frac{\bar{h}_{0}^{5} K_{\zeta_{j}}}{K_{\zeta_{0}}^{2}}\right) \frac{\partial^{2} \bar{p}_{0}}{\partial \theta \partial \zeta}+\frac{13}{1680}\left(\frac{4 \bar{h}_{0}^{3} h_{j}}{K_{\zeta_{0}}} \frac{\partial \bar{h}_{0}}{\partial \theta}-\frac{\bar{h}_{0}^{4} K_{\zeta_{j}}}{K_{\zeta_{0}}^{2}} \frac{\partial \bar{h}_{0}}{\partial \theta}\right.$

$\left.+\frac{\bar{h}_{0}^{4}}{K_{\zeta_{0}}} \frac{\partial \bar{h}_{j}}{\partial \theta}\right)\left(\frac{\partial \bar{p}_{0}}{\partial \zeta}\right)-\frac{1}{560}\left(\frac{6 \bar{h}_{0}^{5} h_{j}}{K_{\zeta_{0}}^{2}} \frac{\partial \bar{h}_{0}}{\partial \zeta}-\frac{2 \bar{h}_{0}^{6} K_{\zeta_{j}}}{K_{\zeta_{0}}^{3}} \frac{\partial \bar{h}_{0}}{\partial \zeta}+\frac{\bar{h}_{0}^{6}}{K_{\zeta_{0}}^{2}} \frac{\partial \bar{h}_{j}}{\partial \zeta}\left(\frac{\partial \bar{p}_{0}}{\partial \zeta}\right)^{2}\right.$

$+\frac{13}{840}\left(\frac{4 \bar{h}_{0}^{3} h_{j}}{K_{\zeta_{0}}} \frac{\partial \bar{h}_{0}}{\partial \tau}-\frac{\bar{h}_{0}^{4} K_{\zeta_{j}}}{K_{\zeta_{0}}^{2}} \frac{\partial \bar{h}_{0}}{\partial \tau}+i \frac{\bar{h}_{0}^{4} \bar{h}_{j}}{K_{\zeta_{0}}}\right)\left(\frac{\partial \bar{p}_{0}}{\partial \zeta}\right)$

$j=1 \quad$ for $\quad \bar{p}_{11} \quad \& \quad j=2 \quad$ for $\quad \bar{p}_{12}$

where, $\quad h_{1}=\cos \theta \quad, \quad h_{2}=\sin \theta$ and $i=\sqrt{-1}$

The pressure drop at the inlet seal edge has been taken into account for tapered seal following Childs and Dressman $^{6)}$ as expressed below:

$$
\Delta p=\left(\frac{1+\xi}{(1+q)^{2}}\right) \frac{\rho V^{2}}{2}
$$

where $\xi$ is the entrance loss coefficient due to loss of kinetic energy at seal entrance usually taken as 0.1 or 0.5 or -0.5 and $q=0$ for parallel seal.

$P V^{2} / 2$ can be calculated from the equation given 
below

$$
\frac{d p_{0}}{d \zeta}=-\frac{\rho \sigma V^{2}}{f_{1}^{3}}\left[1+2 \beta\left(1-2 \zeta \frac{R}{L}\right) q\right]-\frac{2 q \rho V^{2}}{f_{1}^{3}}
$$

where,

$$
\left\{\begin{array}{l}
f_{1}=1+q-2 q \zeta \frac{R}{L}, \lambda_{d}=n_{0} R_{a}^{m_{0}}\left(1+\frac{1}{4 b^{2}}\right)^{\left(\frac{1+m_{0}}{2}\right)} \\
b=R_{a} / R_{c}, \beta=\frac{1}{1+4 b^{2}}, \sigma=\frac{\lambda_{d} L}{C}, \Delta \bar{p}=\Delta p / p_{a} \Lambda
\end{array}\right.
$$

Boundary conditions for the Reynolds equation (8) are given as below:

$$
\begin{aligned}
& \bar{p}_{0}=\bar{p}_{\text {in }}-\Delta \bar{p} \quad \text { at } \zeta=0 \\
& \bar{p}_{0}=\bar{p}_{e x} \quad \text { at } \zeta=L / R \\
& \bar{p}_{0}(\zeta, \theta)=\bar{p}_{0}(\zeta, \theta+2 \pi)
\end{aligned}
$$

Boundary conditions for the Reynolds equation (11) are given as below:

$$
\begin{aligned}
& \bar{p}_{10}=\bar{p}_{0} \quad \text { at } \zeta=0 \\
& \bar{p}_{10}=\bar{p}_{e x} \quad \text { at } \quad \zeta=L / R \\
& \bar{p}_{10}(\zeta, \theta)=\bar{p}_{10}(\zeta, \theta+2 \pi)
\end{aligned}
$$

Dynamic boundary conditions for the solution of perturbed equations (12) at seal inlet and exit are given below:

$$
\begin{aligned}
\bar{p}_{11} & =\bar{p}_{12}=-\frac{(1+\xi) U_{z_{10}} \rho V^{2}}{2 b(1+q) \Lambda p_{a}} \quad \text { at } \zeta=0 \\
; \quad \bar{p}_{11} & =\bar{p}_{12}=\bar{p}_{e x} \quad \text { at } \zeta=L / R
\end{aligned}
$$

where, $U_{z 10}$ is the first order perturbation velocity in axial direction.

\subsection{Stiffness and damping characteristics}

The dynamic force is the useful measure of rotor dynamic coefficients of the system. The shaft vibration severity can be judged by the level of dynamic forces created by shaft motion. Dynamic forces due to ' $P_{11}$ ' are determined as:

$$
\left\{\begin{array}{l}
W_{1 R} e^{i \tau}=\int_{0}^{L / R 2 \pi} \int_{0} C \varepsilon_{1} e^{i \tau} p_{11} R^{2} \cos \theta d \theta d \zeta=-K_{x x} y_{x}-D_{x x} \frac{d y_{x}}{d t} \\
W_{1 T} e^{i \tau}=\int_{0}^{L R 2 \pi} \int_{0}^{2 \pi} C \varepsilon_{1} e^{i \tau} p_{11} R^{2} \sin \theta d \theta d \zeta=-K_{y x} y_{x}-D_{y x} \frac{d y_{x}}{d t}
\end{array}\right.
$$

where $K_{x x}$ and $K_{y x}$ are direct and cross stiffness respectively and $D_{x x}$ and $D_{y x}$ are direct and cross damping terms.

Similarly, the component of the restoring dynamic load in the radial and tangential directions due to the perturbed film pressure ' $P_{12}$ ' can be written as follows

$$
\left\{\begin{array}{l}
W_{2 R} e^{i \tau}=\int_{0}^{L R 2 \pi} \int_{0}^{L / R 2 \pi} C \varepsilon_{0} \varphi e^{i \tau} p_{12} R^{2} \cos \theta d \theta d \zeta=-K_{y x} y_{y}-D_{y x} \frac{d y_{y}}{d t} \\
W_{2 T} e^{i \tau}=\int_{0}^{2} \int_{0}^{2} C \varepsilon_{0} \varphi_{1} e^{i \tau} p_{12} R^{2} \sin \theta d \theta d \zeta=-K_{y y} y_{y}-D_{y y} \frac{d y_{y}}{d t}
\end{array}\right.
$$

where $K_{y x}$ and $K_{y y}$ are cross and direct stiffness respectively and $D_{y x}$ and $D_{y y}$ are cross and direct damping terms.

And the amplitude of oscillation of the journal center in the direction of eccentricity and along the direction perpendicular to that of eccentricity is given as

$$
y_{x}=C \varepsilon_{1} e^{i \tau} \text { and } y_{y}=C \varepsilon_{0} \varphi_{1} e^{i \tau}
$$

\subsection{Whirl ratio}

The stability of a rigid rotor can be determined for centered operation following linear vibration theory in terms of whirl ratio as below ${ }^{11)}$.

$$
f=\frac{\sqrt{d_{1}}}{\Omega}
$$

where, $d_{1}=\frac{\left(d_{2}-K_{x x}\right)\left(d_{2}-K_{y y}\right)-K_{x y} K_{y x}}{D_{x x} D_{y y}-D_{x y} D_{y x}}$

$\& \quad d_{2}=\frac{K_{x x} D_{y y}+K_{y y} D_{x x}-K_{x y} D_{y x}-K_{y x} D_{x y}}{D_{x x}+D_{y y}}$

\subsection{Leakage flow}

Leakage flow in dimensionless form is expressed as:

$$
Q=-\int_{0}^{2 \pi} \frac{\bar{h}^{3}}{K_{\zeta}} \frac{\partial \bar{p}}{\partial \zeta} d \theta \quad \text { at }\left.\quad \frac{\partial \bar{p}}{\partial \zeta}\right|_{\zeta=L / R}
$$

\section{Computational procedure}

Prior to determining the pressure distribution including the fluid inertia effect as given by Eq. (11), it is necessary to solve Eq. (8) to determine the steady state pressure distribution neglecting fluid inertia effects. Equations (8), (11) and (12) are expressed in a finite difference form and are solved satisfying appropriate boundary conditions given by Eqs. (15), (16) and (17) respectively following the Gauss-Siedel iteration process with a relaxation factor generally less than 1 .

Steady state pressures obtained from the solution of Eqs. (8) and (11) were taken as converged when the largest error obtained from two successive iterations was less than 0.0001 . However, the number of iterations required to arrive at a converged solution of Eq. (12) to determine dynamic pressures $\bar{p}_{11}$ and $\bar{p}_{12}$ was determined after carrying out several computations. It was established that 250 iterations were generally more than sufficient to obtain a converged solution. Computations were performed on a Pentium 4 desk top computer. 


\section{Results and discussion}

4.1. Comparison of results with available theoretical and experimental results

In this section some of the computed results of the present investigation for a parallel, circular seal are compared with the theoretical results of Childs ${ }^{5)}$ and Childs and Dressman ${ }^{6}$. Results have been presented for both low and high speed seals. Comparisons with low speed water seals have been presented in part ' $a$ ' and ' $b$ ' of Table 1 for different inlet pressure loss coefficients. The results in 'c' for a high pressure fuel turbo-pump (HPFTP) seal have been compared with the results reported by Child ${ }^{5}$.

Table 1 reveal that the results of rotor dynamic coefficients viz. direct stiffness, direct damping and cross damping coefficients are in reasonably good agreement with the results of Childs ${ }^{5)}$ and Childs and Dressman $^{6}$. However, the cross stiffness coefficients obtained from the present investigation are significantly below the results of Childs and Childs and Dressman ${ }^{5,6}$. In the case of the HPFTP seal which is a high pressure, high speed seal for low viscosity and low density fluid viz. liquid hydrogen, it may be seen that cross stiffness and cross damping coefficients are significantly lower than the results of Childs ${ }^{5)}$ whereas direct stiffness and direct damping coefficients obtained from the present investigation are in good agreement with the results of Childs ${ }^{5)}$. This is a situation in which the flow has a high axial Reynolds number which is due to high pressure drop across the seal. As far as the axial Reynolds number is concerned, the values calculated using an average axial velocity are reasonably close to the values reported by $\mathrm{Childs}^{5}$. For example, the values obtained in the present calculation are $R_{a}=300546$ and $\sigma=0.885$ whereas those obtained by Childs ${ }^{5)}$ are $R_{a}=328000, \sigma=$ 0.865 . For parallel circular water seal with an inlet loss coefficient $\xi=0.0$, the values of axial Reynolds number and $\sigma$ obtained in the present investigation are $R_{a}=9117$ and $\sigma=0.995$ respectively whereas those obtained by Childs and Dressman ${ }^{6}$ are $R_{a}=11835$ and $\sigma=1.138$ which are in reasonably good agreement. Lower values of cross coupled rotor dynamic coefficients obtained in the present calculations may be due to basic difference between the present theoretical analysis and that of bulk flow Hirs theory as used in Ref. [5]. The basic difference between the two approaches is that Childs have adopted Hirs' lubrication theory which is based on the average flow velocity and does not allow velocity variations across the fluid film whereas the present approach follows Reynolds lubrication theory which accommodates a velocity profile across the fluid film. Cross dynamic coefficients are generally due to hydrodynamic effect caused by the rotation of the journal and are usually insignificant at zero and low eccentricity ratios since the fluid forces generated due to hydrodynamic action is very low in comparison to hydrostatic forces due to the pressure drop across the seal. Prediction of low cross dynamic coefficients is expected in the formulation following fluid film lubrication theory which uses the Reynolds Equation. The flow in annular seal is predominantly due to an axial pressure gradient and therefore a hydrodynamic or rotation effect would be significant at high speeds only.

Comparison of theoretical results for short circular seals under eccentric operation with the experimental results of Marquette et al. ${ }^{24)}$ are given in Table 2(a)-(d). It can be opined that the results obtained for dynamic coefficients of the seal are in reasonably good agreement with the experimental results for short seals. However, in the leakage flow the discrepancy between present theory and experimental results are somewhat more. This could be because of very short seal length used in the experiments. The pressure drop due to inertia at the seal entrance may be more resulting in lower values of leakage flow in the experimental results. Entrance loss coefficients used in the calculations may also influence the leakage flow and dynamic coefficients in the calculations done. The discrepancies between theory and experiments could also be due to this to a considerable extent.

\section{Table 1}

\section{a: Water Seal ,Childs ${ }^{5)}$}

$\mathrm{D}=0.0798 \mathrm{~m}, \mathrm{~L}=0.0432 \mathrm{~m}, \mathrm{C}=2.967 * 10^{-4} \mathrm{~m}, \mathrm{RPM}=3,600$, $\rho=1000 \mathrm{~kg} / \mathrm{m}^{3}, \mu=1.295^{*} 10^{-3} \mathrm{~Pa}-\mathrm{s}, \Delta \mathrm{p}=1.035^{*} 10^{6} \mathrm{~Pa}$, $\mathrm{C}_{\mathrm{i}}=\mathrm{C}, \xi=-0.5, \lambda_{t}=0.83$

\begin{tabular}{|c|c|c|c|c|}
\hline & $\begin{array}{c}\mathrm{K}_{\mathrm{xx}} * 10^{-6} \\
(\mathrm{~N} / \mathrm{m})\end{array}$ & $\begin{array}{c}\mathrm{K}_{\mathrm{yx}} * 10^{-6} \\
(\mathrm{~N} / \mathrm{m})\end{array}$ & $\begin{array}{c}\mathrm{D}_{\mathrm{xx}} \\
(\mathrm{Ns} / \mathrm{m})\end{array}$ & $\begin{array}{c}\mathrm{D}_{\mathrm{yx}} \\
(\mathrm{Ns} / \mathrm{m})\end{array}$ \\
\hline Childs & 2.889 & 2.047 & 10,860 & 2,468 \\
\hline Present & 3.241 & 1.130 & 8,599 & 3,009 \\
\hline
\end{tabular}

\section{b: Water Seal ,Childs and Dressman')}

\section{$\mathrm{D}=0.0798 \mathrm{~m}, \mathrm{~L}=0.0432 \mathrm{~m}, \mathrm{C}=2.967 * 10^{-4} \mathrm{~m}, \mathrm{RPM}=3,600$,} $\rho=1000 \mathrm{~kg} / \mathrm{m}^{3}, \mu=1.245^{*} 10^{-3} \mathrm{~Pa}-\mathrm{s}, \Delta \mathrm{p}=1.035^{*} 10^{6} \mathrm{~Pa}$,

$\mathrm{C}_{\mathrm{i}}=\mathrm{C}, \xi=0.0, \quad \lambda_{t}=0.83$

\begin{tabular}{|l|c|c|c|c|}
\hline & $\begin{array}{l}\mathrm{K}_{\mathrm{xx}} * 10^{-6} \\
(\mathrm{~N} / \mathrm{m})\end{array}$ & $\begin{array}{l}\mathrm{K}_{\mathrm{yx}} * 10^{-6} \\
(\mathrm{~N} / \mathrm{m})\end{array}$ & $\begin{array}{l}\mathrm{D}_{\mathrm{xx}} \\
(\mathrm{Ns} / \mathrm{m})\end{array}$ & $\begin{array}{l}\mathrm{D}_{\mathrm{yx}} \\
(\mathrm{Ns} / \mathrm{m})\end{array}$ \\
\hline $\begin{array}{l}\text { Childs- } \\
\text { Dressman }\end{array}$ & 2.614 & 1.854 & 9,837 & 2,174 \\
\hline Present & 2.591 & 0.845 & 6,876 & 2,241 \\
\hline
\end{tabular}

c:HPFTP,Childs ${ }^{5)}, \mathrm{D}=0.0798 \mathrm{~m}, \mathrm{~L}=0.0432 \mathrm{~m}, \xi=0.0$, $\mathrm{C}=1.397 * 10^{-4} \mathrm{~m}, \mathrm{RPM}=37,360, \mathrm{C}_{\mathrm{i}}=\mathrm{C}, \lambda_{t}=0.97$, $\rho=70.78 \mathrm{~kg} / \mathrm{m}^{3}, \mu=1.16^{*} 10^{-5} \mathrm{~Pa}-\mathrm{s}, \Delta \mathrm{p}=1.492 * 10^{7} \mathrm{~Pa}$

\begin{tabular}{|l|c|c|c|c|}
\hline & $\begin{array}{l}\mathrm{K}_{\mathrm{xx}}^{*} 10^{-8} \\
(\mathrm{~N} / \mathrm{m})\end{array}$ & $\begin{array}{l}\mathrm{K}_{\mathrm{yx}} * 10^{-8} \\
(\mathrm{~N} / \mathrm{m})\end{array}$ & $\begin{array}{l}\mathrm{D}_{\mathrm{xx}} \\
(\mathrm{Ns} / \mathrm{m})\end{array}$ & $\begin{array}{l}\mathrm{D}_{\mathrm{yx}} \\
(\mathrm{Ns} / \mathrm{m})\end{array}$ \\
\hline Childs & 0.902 & 0.441 & 22,540 & 3,767 \\
\hline Present & 1.00 & 0.077 & 25,667 & 1,971 \\
\hline
\end{tabular}


Table 2(a):

(Present Calculations)

\begin{tabular}{l}
\begin{tabular}{|c|l|l|l|l|l|}
\hline Leakage Flow 'Q' (1t/s), $\xi=0.1, \mathrm{RPM}=10,200$ \\
\hline Pr. drop & $\varepsilon=0.0$ & $\varepsilon=0.1$ & $\varepsilon=0.2$ & $\varepsilon=0.3$ & $\varepsilon=0.4$ \\
\hline $4.14 \mathrm{MPa}$ & 1.33 & 1.33 & 1.35 & 1.39 & 1.44 \\
\hline $5.52 \mathrm{MPa}$ & 1.75 & 1.75 & 1.77 & 1.82 & 1.89 \\
\hline (Marquette et al.) & $\mathbf{5}$ \\
\hline
\end{tabular} \\
\hline \begin{tabular}{|c|l|l|l|l|l|} 
Leakage Flow 'Q' (lt/s), $\xi=0.1, \mathrm{RPM}=10,200$ \\
\hline Pr. drop & $\varepsilon=0.0$ & $\varepsilon=0.1$ & $\varepsilon=0.2$ & $\varepsilon=0.3$ & $\varepsilon=0.4$ \\
\hline $4.14 \mathrm{MPa}$ & 0.83 & 0.83 & 0.84 & 0.85 & 0.86 \\
\hline $5.52 \mathrm{MPa}$ & 0.98 & 0.99 & 1.00 & 1.01 & 1.02 \\
\hline
\end{tabular}
\end{tabular}

\section{Table 2(b):}

(Present Calculations)

\begin{tabular}{|c|c|c|c|c|c|}
\hline \multicolumn{6}{|c|}{ Direct stiffness' $\mathrm{K}_{\mathrm{xx}}{ }^{\prime}(\mathrm{MN} / \mathrm{m}), \xi=0.1, \mathrm{RPM}=10,200$} \\
\hline Pr. drop & $\varepsilon=0.0$ & $\varepsilon=0.1$ & $\varepsilon=0.2$ & $\varepsilon=0.3$ & $\varepsilon=0.4$ \\
\hline $4.14 \mathrm{MPa}$ & 20.58 & 17.86 & 16.08 & 15.18 & 15.30 \\
\hline $5.52 \mathrm{MPa}$ & 32.57 & 26.86 & 22.86 & 20.50 & 20.11 \\
\hline \multicolumn{6}{|c|}{ Marquette et al.) ${ }^{24)}$} \\
\hline \multicolumn{6}{|c|}{ Direct stiffness' $\mathrm{K}_{\mathrm{xx}}{ }^{\prime}(\mathrm{MN} / \mathrm{m}), \xi=0.1, \mathrm{RPM}=10,200$} \\
\hline Pr. drop & $\varepsilon=0.0$ & $\varepsilon=0.1$ & $\varepsilon=0.2$ & $\varepsilon=0.3$ & $\varepsilon=0.4$ \\
\hline $4.14 \mathrm{MPa}$ & 19.30 & 19.30 & 19.00 & 18.90 & 18.80 \\
\hline $5.52 \mathrm{MPa}$ & 26.10 & 26.20 & 26.30 & 26.40 & 26.50 \\
\hline
\end{tabular}

\section{Table 2(c):}

\section{(Present Calculations)}

\begin{tabular}{|c|l|l|l|l|l|}
\hline \multicolumn{6}{|c|}{ Cross stiffness' $\mathrm{K}_{\mathrm{xy}}{ }^{\prime}(\mathrm{MN} / \mathrm{m}), \xi=0.1, \mathrm{RPM}=10,200$} \\
\hline Pr. drop & $\varepsilon=0.0$ & $\varepsilon=0.1$ & $\varepsilon=0.2$ & $\varepsilon=0.3$ & $\varepsilon=0.4$ \\
\hline $4.14 \mathrm{MPa}$ & 2.77 & 2.60 & 2.48 & 2.36 & 2.22 \\
\hline $5.52 \mathrm{MPa}$ & 5.35 & 5.18 & 5.02 & 4.83 & 4.58 \\
\hline
\end{tabular}

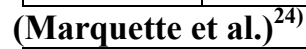

Cross stiffness ' $\mathrm{K}_{\mathrm{xy}}$ '(MN/m), $\xi=0.1, \mathrm{RPM}=10,200$

\begin{tabular}{|c|c|c|c|c|c|}
\hline Pr. drop & $\varepsilon=0.0$ & $\varepsilon=0.1$ & $\varepsilon=0.2$ & $\varepsilon=0.3$ & $\varepsilon=0.4$ \\
\hline
\end{tabular}

\begin{tabular}{|l|l|l|l|l|l|}
\hline $4.14 \mathrm{MPa}$ & 8.40 & 8.60 & 8.70 & 8.90 & 9.20 \\
\hline
\end{tabular}

\begin{tabular}{|l|l|l|l|l|l|}
\hline $5.52 \mathrm{MPa}$ & 8.40 & 8.70 & 8.80 & 9.20 & 9.30 \\
\hline
\end{tabular}

\section{Table 2(d):}

\section{(Present Calculations)}

\begin{tabular}{|c|c|c|c|c|c|}
\hline \multicolumn{6}{|c|}{ Direct damping ' $\mathrm{D}_{\mathrm{xx}}{ }^{\prime}(\mathrm{kNs} / \mathrm{m}), \xi=0.1, \mathrm{RPM}=10,200$} \\
\hline Pr. drop & $\varepsilon=0.0$ & $\varepsilon=0.1$ & $\varepsilon=0.2$ & $\varepsilon=0.3$ & $\varepsilon=0.4$ \\
\hline $4.14 \mathrm{MPa}$ & 19.27 & 16.72 & 15.05 & 14.21 & 14.32 \\
\hline $5.52 \mathrm{MPa}$ & 30.49 & 25.14 & 21.40 & 19.19 & 18.83 \\
\hline \multicolumn{6}{|c|}{ Marquette et al.) ${ }^{24)}$} \\
\hline \multicolumn{6}{|c|}{ Direct damping ${ }^{\prime} \mathrm{D}_{\mathrm{xx}}{ }^{\prime}(\mathrm{kNs} / \mathrm{m}), \xi=0.1, \mathrm{RPM}=10,200$} \\
\hline Pr. drop & $\varepsilon=0.0$ & $\varepsilon=0.1$ & $\varepsilon=0.2$ & $\varepsilon=0.3$ & $\varepsilon=0.4$ \\
\hline $4.14 \mathrm{MPa}$ & 19.55 & 19.85 & 20.10 & 20.40 & 20.50 \\
\hline $5.52 \mathrm{MPa}$ & 24.10 & 24.30 & 24.80 & 25.20 & 26.40 \\
\hline
\end{tabular}

\subsection{Wavy seal results}

Results are presented for a wave annular seal with following dimensions: journal diameter $=76.29 \mathrm{~mm}$, radial seal clearance $=0.11 \mathrm{~mm}$, seal length $=34.93 \mathrm{~mm}$, inlet loss coefficient $=0.1$, surface finish - smooth. Results are also presented for a three wave annular seal for various L/D ratios, taper ratios and wave eccentricity ratios with journal speed varying between 10,000 and
$25,000 \mathrm{rpm}$. The lubricant used in the present calculations is water having a density of $1,000 \mathrm{~kg} / \mathrm{m}^{2}$ and absolute viscosity $0.001245 \mathrm{~Pa}$. The pressure drop across the seal is $4.14 \mathrm{MPa}$. The value of perturbation parameter $\lambda_{t}$ varied between 0.32 and 0.40 .

The effect of the L/D ratio has been highlighted in an annular wave seal in concentric operation for a wave eccentricity ratio of 0.2 in Figs. 4-9. Leakage flow variation with speed is shown in Fig. 4. There is a marked influence of the $\mathrm{L} / \mathrm{D}$ ratio on the leakage flow of the wavy seal. It is observed that leakage flow decreases very significantly with an increase in the $L / D$ ratio. Increase in the length of the seal reduces the axial pressure gradient for a particular pressure drop across the seal and thus reduces the leakage flow. Leakage flow also reduces with increase in the speed of rotation of the journal. Since the rotation of the journal results in screw flow, which increases the flow path of the fluid in the axial direction and increases the effective viscosity due to the increase in Reynolds number, there is a reduction of the leakage flow.

Figures 5 and 6 present the variation of direct stiffness and cross stiffness of the seal with rotation speed for various L/D ratios. Here again it is observed that both direct and cross stiffness increase substantially with an increase in the length to diameter ratio. On the other hand the increase with speed of these parameters is not of the same magnitude. The cross stiffness values

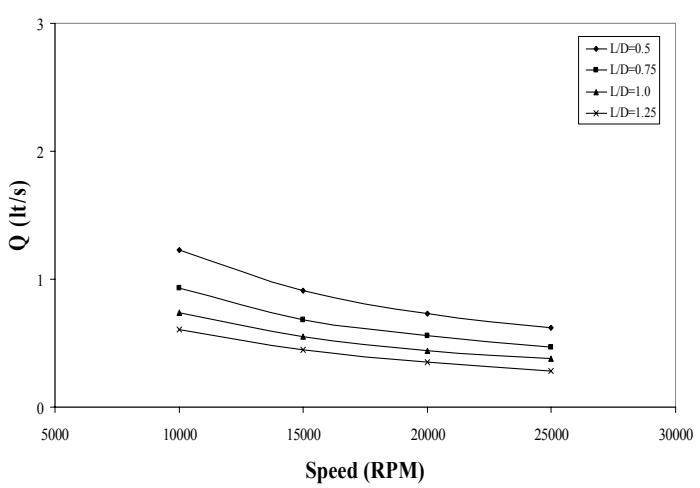

Fig. 4 Leakage flow vs. speed for various L/D ratio, $\gamma=1.0, \varepsilon_{\omega}=0.2, \alpha_{1}=0, \varepsilon=0.0$

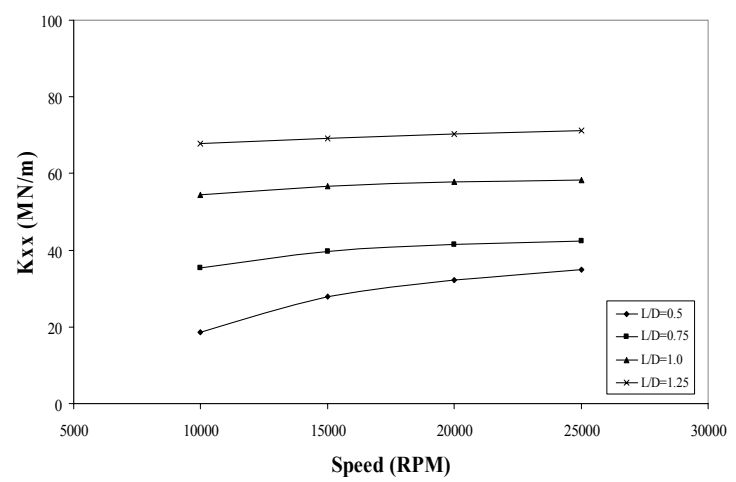

Fig. 5 Direct stiffness vs. speed for various $\mathrm{L} / \mathrm{D}$ ratio, $\gamma=1.0, \varepsilon_{\omega}=0.2, \alpha_{1}=0, \varepsilon=0.0$ 


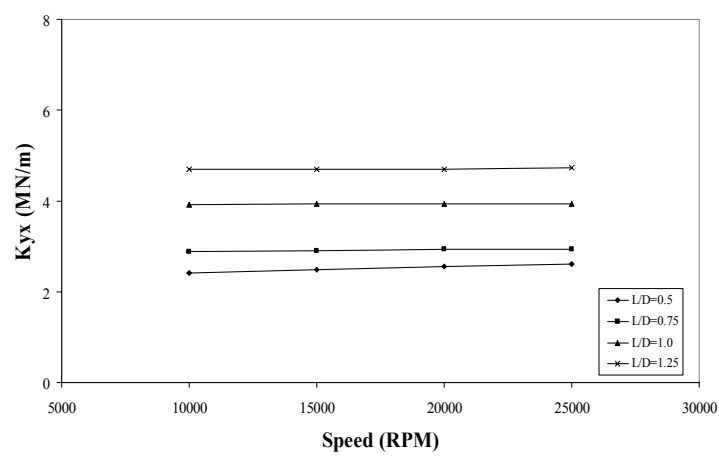

Fig. 6 Cross stiffness vs. speed for various L/D ratio, $\gamma=1.0, \varepsilon_{\omega}=0.2, \alpha_{1}=0, \varepsilon=0.0$

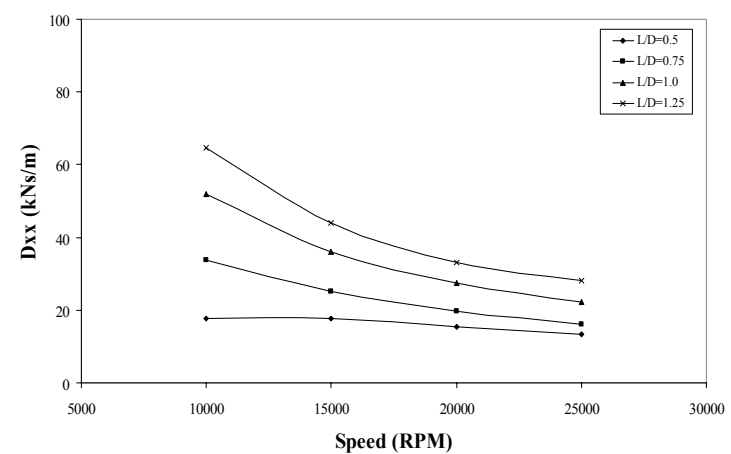

Fig. 7 Direct damping vs. speed for various $\mathrm{L} / \mathrm{D}$ ratio, $\gamma=1.0, \varepsilon_{\omega}=0.2, \alpha_{1}=0, \varepsilon=0.0$

are an order of magnitude lower than the direct stiffness.

The influence of the L/D ratio and speed of rotation of the journal on damping coefficients are shown in Figs. 7 and 8. Both direct and cross damping reduce with increase in speed. But, it is observed that damping coefficients increase substantially. Whirl ratio variations are shown in Fig. 9. The whirl ratio is low which indicates that seals are generally stable components. Whirl ratio decreases with increase in length to diameter ratio which is compatible with increase in direct stiffness and damping also.

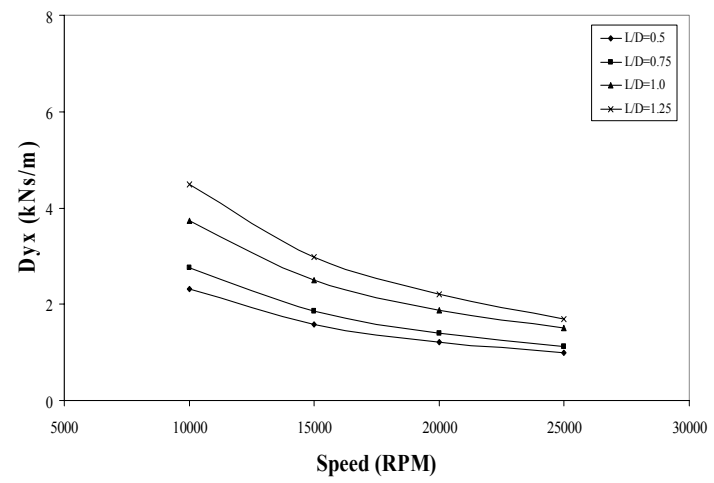

Fig. 8 Cross damping vs. speed for various $\mathrm{L} / \mathrm{D}$ ratio, $\gamma=1.0, \varepsilon_{\omega}=0.2, \alpha_{1}=0, \varepsilon=0.0$

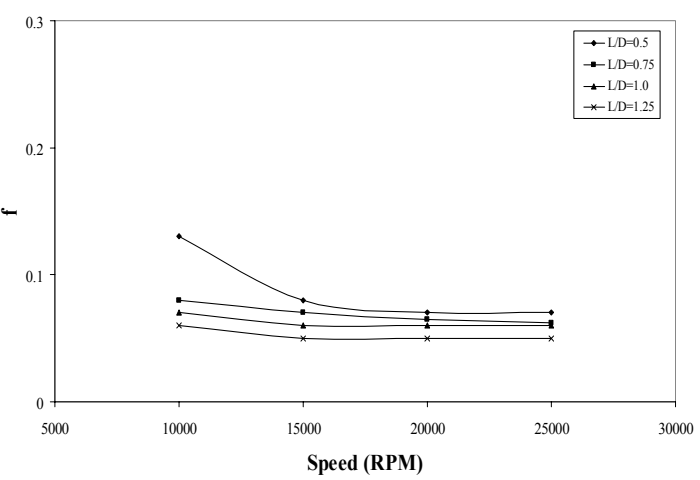

Fig. 9 Whirl ratio vs. speed for various L/D ratio, $\gamma=1.0, \varepsilon_{\omega}=0.2, \alpha_{1}=0, \varepsilon=0.0$

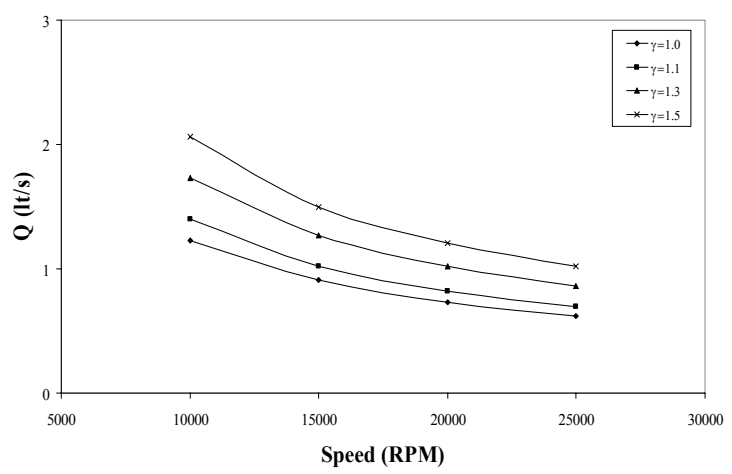

Fig. 10 Leakage flow vs. speed for various $\gamma$, $\mathrm{L} / \mathrm{D}=0.5, \varepsilon_{\omega}=0.2, \alpha_{1}=0, \varepsilon=0.0$

The influences of taper ratio i.e. the ratio of the inlet to exit radial clearance of the seal are shown in Figs. 10-15. The general trend of the results is consistent with the accepted behavior of tapered annular seals available in the literature.

In Fig. 10, it is seen that with taper ratio leakage flow increases. This is because higher taper ratio means an increase in the clearance volume. Figures 11 and 12 present the variation of direct and cross stiffness with taper ratio. It is observed that taper ratio substantially raises the direct stiffness whereas the cross stiffness rise only marginally.

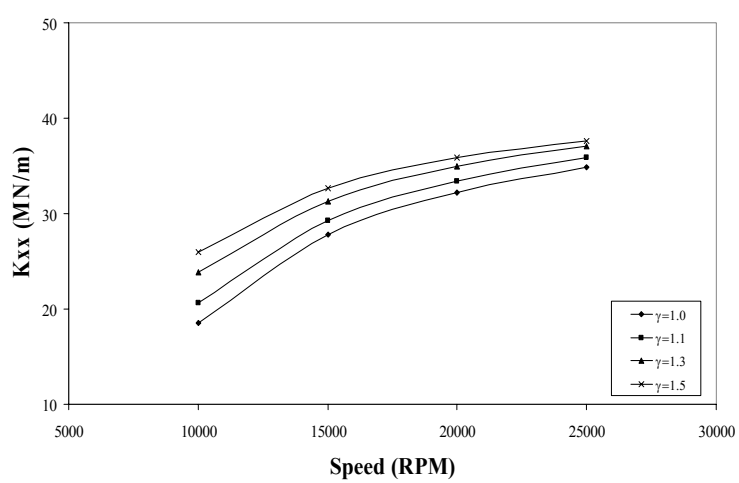

Fig. 11 Direct stiffness vs. speed for various $\gamma$, $\mathrm{L} / \mathrm{D}=0.5, \varepsilon_{\omega}=0.2, \alpha_{1}=0, \varepsilon=0.0$ 


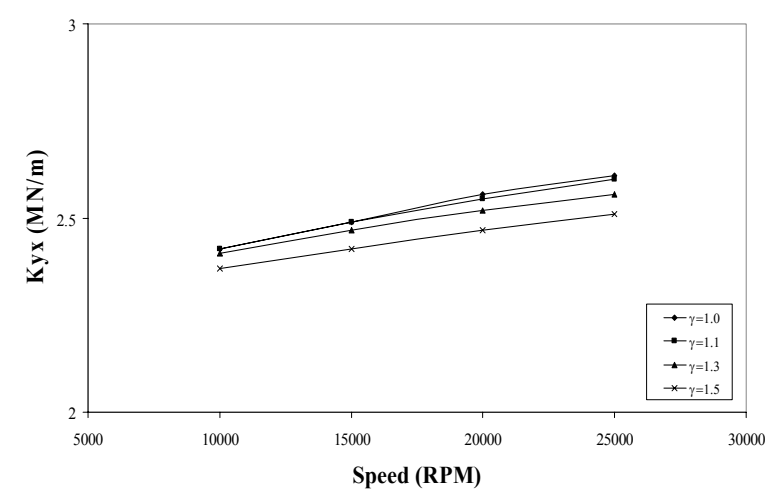

Fig. 12 Cross stiffness vs. speed for various $\gamma$, $\mathrm{L} / \mathrm{D}=0.5, \varepsilon_{\omega}=0.2, \alpha_{1}=0, \varepsilon=0.0$

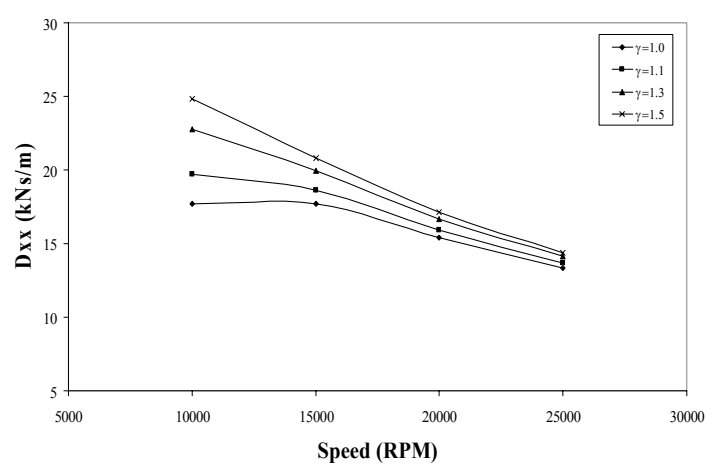

Fig. 13 Direct damping vs. speed for various $\gamma$, $\mathrm{L} / \mathrm{D}=0.5, \varepsilon_{\omega}=0.2, \alpha_{1}=0, \varepsilon=0.0$

Figure 13 shows the effect of taper ratio on the direct damping coefficient which depicts a remarked higher value at lower speeds of rotation of the journal whereas at high rotational speeds the influence of taper reduces. On the other hand Fig. 14 shows only marginal influence of taper ratio on cross damping coefficient. Higher values of direct stiffness and direct damping with taper further improves the stability of the seal as can be seen in Fig. 15 which provides the variation in whirl ratio with increase in taper.

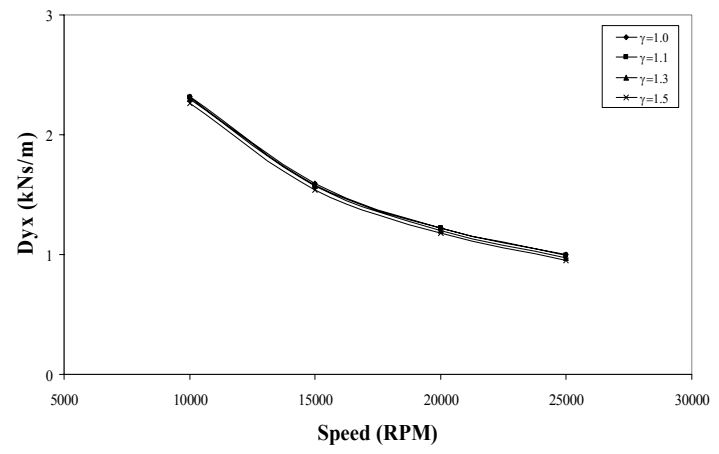

Fig. 14 Cross damping vs. speed for various $\gamma$, $\mathrm{L} / \mathrm{D}=0.5, \varepsilon_{\omega}=0.2, \alpha_{1}=0, \varepsilon=0.0$

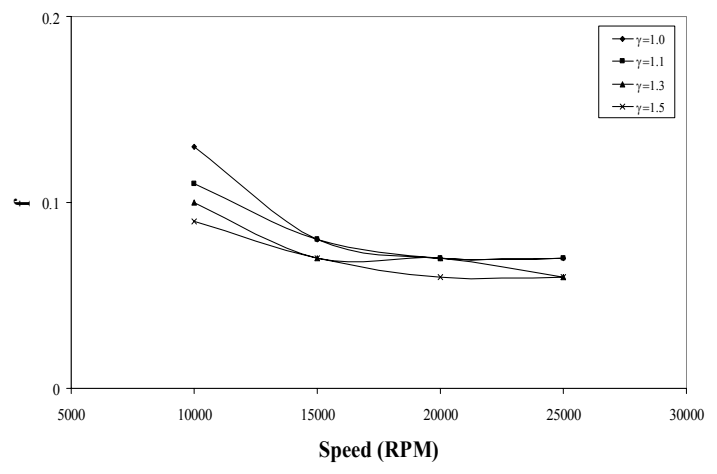

Fig. 15 Whirl ratio vs. speed for various $\gamma$, $\mathrm{L} / \mathrm{D}=0.5, \varepsilon_{\omega}=0.2, \alpha_{1}=0, \varepsilon=0.0$

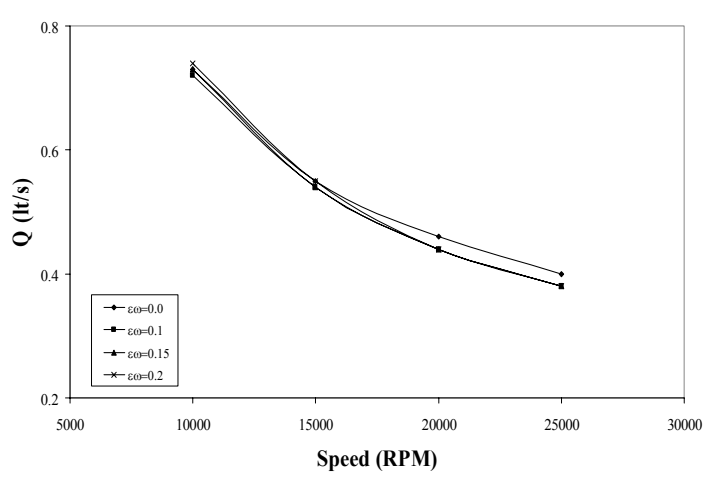

Fig. 16 Leakage flow vs. speed for various $\varepsilon_{\omega}$ ratio, $\mathrm{L} / \mathrm{D}=1.0, \alpha_{1}=0, \varepsilon=0.0$

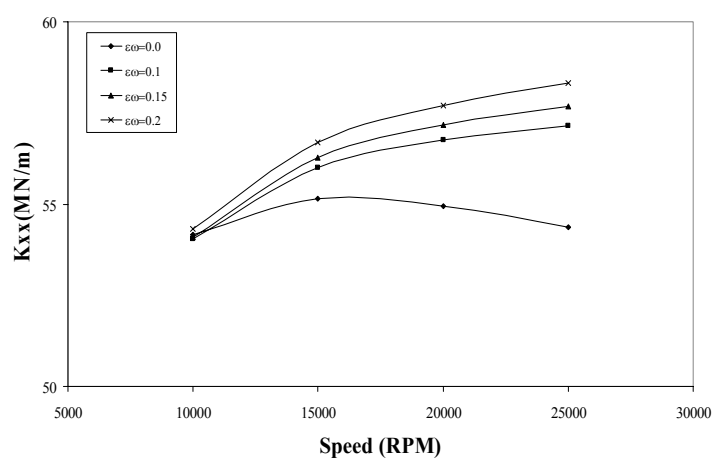

Fig.17 Direct stiffness vs. speed for various $\varepsilon_{\omega}$ ratio, $\mathrm{L} / \mathrm{D}=1.0, \alpha_{1}=0, \varepsilon=0.0$

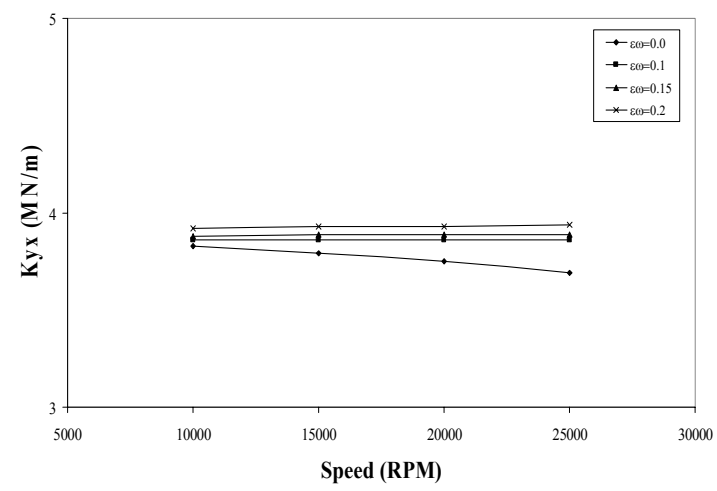

Fig. 18 Cross stiffness vs. speed for various $\varepsilon_{\omega}$ ratio, $\mathrm{L} / \mathrm{D}=1.0, \alpha_{1}=0, \varepsilon=0.0$ 


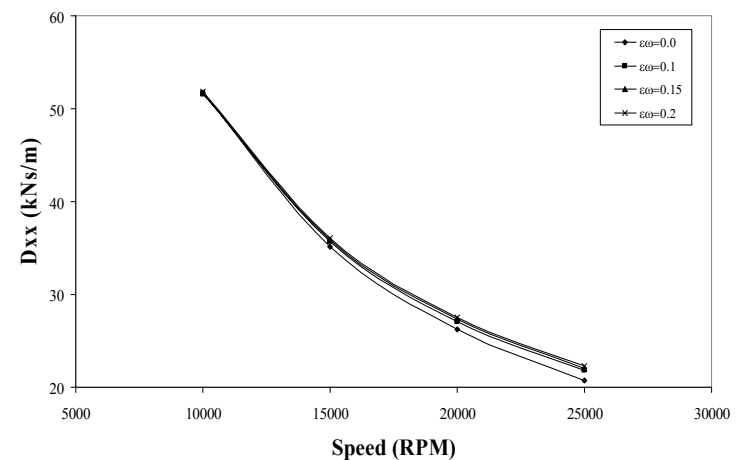

Fig. 19 Direct damping vs. speed for various $\varepsilon_{\omega}$ ratio, $\mathrm{L} / \mathrm{D}=1.0, \alpha_{1}=0, \varepsilon=0.0$

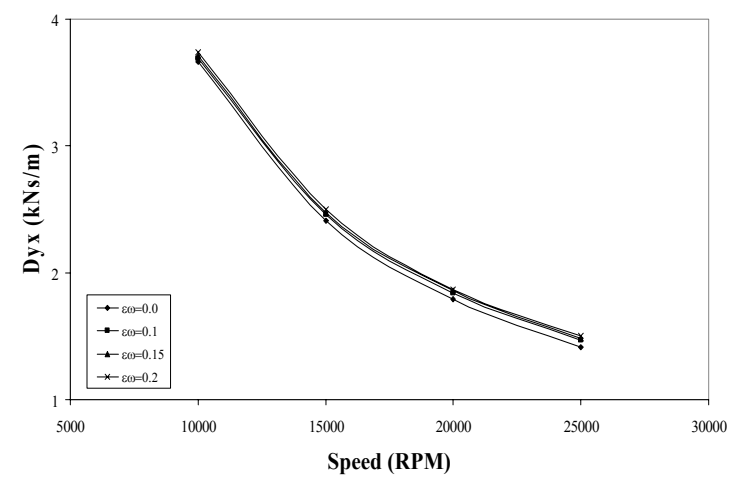

Fig. 20 Cross damping vs. speed for various $\varepsilon_{\omega}$ ratio, $\mathrm{L} / \mathrm{D}=1.0, \alpha_{1}=0, \varepsilon=0.0$

The influence of wave eccentricity ratio on the dynamic characteristics of the wave seal is shown in Figs. 16-20. Except for lower speeds of rotation of the journal the leakage flow reduces with wave eccentricity ratio.

Modification of circumferential geometry of the clearance space influences the seal performance. However, the overall clearance volume is not altered due to waviness. At lower speeds leakage marginally increase with wave eccentricity ratio. Figure 17 shows the influence of waviness on the direct stiffness of the seal. It is observed that wave eccentricity ratio has very significant influence on direct stiffness which increases significantly with wave eccentricity ratio at higher speeds. At lower speeds the effect is marginal. On the other hand Fig. 18 shows relatively less significant effect of wave eccentricity ratio on cross stiffness although cross stiffness shows some increase with wave eccentricity ratio. It can be seen in Figs. 19 and 20 that cross damping coefficients have only a marginal variation with increase in wave eccentricity ratio at higher speeds only.

The general observation obtained from the results presented is that $\mathrm{L} / \mathrm{D}$ ratio and taper ratio have larger influence on the dynamic characteristics of annular seals and the effect would be similar for both circular and wavy seals. Wavy geometry may improve the stability of the seal at higher speeds with some reduction in the seal leakage too. This is due to enhanced direct stiffness which contributes towards stability and very marginal change in cross stiffness which contributes towards instability. Reduction of leakage is one of the major considerations in the design of a seal.

\section{Summary}

A theoretical procedure to calculate leakage flow and rotor dynamic coefficients viz. stiffness and damping of annular seals in turbulent flow accounting for fluid inertia effects based on turbulent lubrication theory has been presented. The analysis is based on a perturbation approach to account for fluid inertia in the film and also takes in to account velocity variations across the fluid film through a velocity profile as opposed to the bulk flow approach that has been used by others. The procedure is general and geometric effects can be incorporated through the film shape description. In its present form the analysis however does not account for swirl at the seal entrance. The results of the present analysis for leakage flow, direct stiffness and direct damping coefficients agree reasonably well with the results of other researchers. However, the present analysis produces lower values of cross coefficients in comparison to the results obtained by other researchers. The circumferential wave seal can improve dynamic characteristics of the seal in comparison to the performance of a circular seal. Leakage flow is reduced in a wave seal as compared to circular seal at higher journal speeds. Direct stiffness and direct damping also increase as compared to circular seals over a wide range of speed. Cross stiffness and cross damping change marginally with wave eccentricity ratio. However, both the coefficients decrease with increases in speed. In general dynamic characteristics and stability also improve with increase in both the $\mathrm{L} / \mathrm{D}$ ratio and the taper ratio. However, larger taper ratios increase leakage to some extent whereas leakage reduces significantly with increase in the $\mathrm{L} / \mathrm{D}$ ratio.

\section{Nomenclature}

$b$ Dimensionless coefficient defined in equation (14)

C Radial clearance at the seal exit (m)

$C_{i} \quad$ Radial clearance at the seal entrance (m)

D Dia. of the journal (m)

D... Damping coefficients $(\mathrm{kNs} / \mathrm{m})$,

$\bar{D} \ldots \quad=D C \omega / R^{2} p_{a} \Lambda \quad($ dimensionless $)$

$e \quad$ Eccentricity $(\mathrm{m}), \varepsilon=e / C$

$e_{\omega} \quad$ Wave's amplitude (m), $\varepsilon_{\omega}=e_{\omega} / C$ (dimensionless)

$f \quad$ Whirl ratio $(\omega / \Omega)$

$f_{1} \quad$ Dimensionless clearance defined by equation (14) 


$\begin{array}{ll}h & \text { Film thickness, } \bar{h}=h / C \\ K_{\theta}, K_{\zeta} & \text { Turbulent couette shear factor } \\ K \ldots & \text { Stiffness coefficients }(\mathrm{MN} / \mathrm{m}) \\ & \bar{K} \ldots=K C / R^{2} p_{a} \Lambda(\text { dimensionless }) \\ L & \text { Length of the bearing }(\mathrm{m}) \\ m_{0}, n_{0} & \begin{array}{l}\text { Coefficients for Hirs's turbulent lubrication } \\ \end{array} \\ n_{c w} & \text { equation (14) } \\ p_{0} & \text { Number of circumferential waves }\end{array}$$$
(\mathrm{Pa}), \bar{p}_{0}=p_{0} / \Lambda p_{a}
$$

$p_{1} \quad$ Fluid pressure with inertia $(\mathrm{Pa})$, $\bar{p}_{1}=p_{1} / \Lambda p_{a}$

$p_{10} \quad$ Steady state pressure $(\mathrm{Pa}), \bar{p}_{10}=p_{10} / \Lambda p_{a}$

$p_{11}, p_{12} \quad$ Dynamic film pressures $(\mathrm{Pa})$, $\bar{p}_{11}=p_{11} / \Lambda p_{a} \quad, \quad \bar{p}_{12}=p_{12} / \Lambda p_{a}$

$p_{a} \quad$ Atmospheric pressure $(\mathrm{Pa})$

$p_{\text {in }} \quad$ Inlet pressure $(\mathrm{Pa}), \bar{p}_{i n}=\left(p_{\text {in }} / p_{a} \Lambda\right)$

$p_{e x} \quad$ Exit pressure $(\mathrm{Pa}), \bar{p}_{e x}=p_{e x} / \Lambda p_{a}$

$q \quad$ Taper-angle parameter, $q=\left(C_{i}-C\right) /\left(C_{i}+C\right)$

$Q \quad$ Leakage flow (lt/s)

$R \quad$ Journal radius (m)

$R_{a} \quad$ Axial Reynolds number $(\rho V C / \mu)$

$R_{c} \quad$ Circumferential Reynolds number $(\rho C R \Omega / \mu)$

$t \quad$ Time (sec), $\quad \tau=\omega t$ (dimensionless)

$u, v, w \quad$ Fluid velocity components in cartesian coordinates

$V \quad$ Axial flow velocity $(\mathrm{m} / \mathrm{s})$

$W_{l R}, W_{2 R}$ Radial components of restoring dynamic loads due to dynamic film pressures $p_{11}$ and $p_{12}(\mathrm{~N})$

$W_{1 T}, W_{2 T}$ Transverse components of restoring dynamic loads due to dynamic film pressures $p_{11}$ and $p_{12}(\mathrm{~N})$

$x_{1}, y_{1}, z \quad$ Cartesian coordinates

$\alpha_{1} \quad$ Angle between the starting point of the wave and the line of centers (degrees) in Fig.1.

$\beta \quad$ Dimensionless parameter defined in equation (14)

$\varepsilon_{0}, \varepsilon_{1} \quad$ Steady state and dynamic eccentricity ratios

$\varepsilon^{\prime} \quad$ Eddy diffusivity

$\gamma \quad$ Taper ratio $\left(\mathrm{C}_{\mathrm{i}} / \mathrm{C}\right)$

$\xi \quad$ Inlet pressure-loss coefficient

$\lambda_{t} \quad$ Modified turbulent Reynolds number

$$
\left(\rho C^{2} \Omega / \mu^{*}\right)
$$

$\lambda_{d}$ Dimensionless friction factor defined in equation (14)

$\mu \quad$ Absolute viscosity of the lubricant (Pa-s)

$\mu^{*} \quad$ Effective viscosity, $\mu\left(1+\varepsilon^{\prime} / v\right)$ $v \quad$ Kinematic viscosity of the fluid

$\varphi \quad$ Attitude angle

$\Omega \quad$ Journal speed ( $\mathrm{rad} / \mathrm{s})$

$\rho \quad$ Density of the lubricant $\left(\mathrm{kg} / \mathrm{m}^{3}\right)$

$\sigma \quad=\lambda_{d} L C$, Dimensionless parameter defined in equation (14)

$\theta, \eta, \zeta \quad$ Dimensionless coordinates

$\omega \quad$ Vibration frequency of the journal center $(\mathrm{rad} / \mathrm{s})$

$\Lambda \quad$ Bearing number, $\mu \Omega(R / C)^{2} / p_{a}$

\section{Subscripts}

10,11,12 Zeroeth and first order perturbations along the eccentricity and normal to it respectively.

\section{References}

[1] Ng, C. W. and Pan, C. H. T., "A Linearized Turbulent Lubrication Theory," ASME Journal of Basic Engineering, 87, 1965, 675-688.

[2] Elrod, H. G., and Ng, C. W., "A Theory for Turbulent Fluid Films and Its Application to Bearings," ASME Journal of Lubrication Technology, 89, 3, 1967, 346-362.

[3] Hirs, G. G., "A Bulk Flow Theory for Turbulence in Lubricant Films," ASME Journal of Lubrication Technology, 95, 1973, 137-146.

[4] Black, H. F., "Research Notes on Journal Bearings with High Axial Flows in the Turbulent Regime," Journal of Mechanical Engineering Science, 12, 4, 1970, 301-303.

[5] Childs, D. W., "Dynamic Analysis of Turbulent Annular Seals Based on Hirs' Lubrication Theory," ASME Journal of Lubrication Technology, 105, 1983, 437-445.

[6] Childs, D. W. and Dressman, J. B., "Convergent-Tapered Annular Seals: Analysis and Testing for Rotordynamic Coefficients," ASME Journal of Tribology, 107, 1985, 307- 317.

[7] Lindsay, W. T., and Childs, D., "The Effect of Converging and Diverging Axial Taper on the Rotordynamic Coefficients of Liquid Annular Pressure Seals: Theory Versus Experiment," ASME Journal of Vibration and Acoustics, 122, 2000, 126-131.

[8] Soni, S. C., Sinhasan, R. and Singh, D. V., "Performance Characteristics of Noncircular Bearings in Laminar and Turbulent Flow Regimes," ASLE Transaction, 24, 1981, 29-41.

[9] Vaidyanathan, K. and Keith, T. G. (Jr.), "Performance Characteristics of Cavitated Noncircular Journal Bearings in the Turbulent Flow Regime," STLE Tribology Transaction, 34, 1, 1991, 35-44.

[10] Li, D., Choy, K. and Allaire, P., "Stability and Transient Characteristics of Four Multilobe Journal Bearings," ASME Journal of Lubrication Technology, 102, 1980, 291-299. 
[11] Abdul, W. N., Nicolas, D. and Pascal, M. T., "Stability and Unbalance Response of Large Turbine Bearings," ASME Journal of Lubrication Technology, 104, 1982, 66-75.

[12] Hargreaves, D. J., "Surface Waviness Effects on the Load Carrying Capacity of Rectangular Slider Bearings," Wear, 145, 1991, 137-151.

[13] Hassan, E. R., "Effect of Surface Waviness on the Hydrodynamic Lubrication of a Plain Cylindrical Sliding Element Bearing," Wear, 223, 1998, 1-6.

[14] Dimofte, F., "A Waved Journal Bearing Concept with Steady State and Dynamic Performance," Rotor dynamic Instability Problems in High Performance Turbo Machinery, NASA CP 1036, 1993, 419-429.

[15] Dimofte, F., "Wave Journal Bearing with Compressible Lubricant - Part I: The Wave Bearing Concept and a Comparison to the Plain Circular Bearing," STLE Tribology Transaction, 38, 1995, 153-160.

[16] Dimofte, F., "Wave Journal Bearing with Compressible Lubricant - Part II: A Comparison of the Wave Bearing with Wave Grooved Bearing and Lobe Bearing," STLE Tribology Transaction., 38,2, 1995, 364-372.

[17] Lambrulescu, M. I., Dimofte, F. and Sawicki, J. T., "Experimental Investigation on the Influence of Oil Inlet Pressure on the Stability of Wave Journal Bearing," The $10^{\text {th }}$ International Symposium on Transport Phenomena and Dynamics of Rotating Machinery (ISROMAC-10), Honolulu, Hawaii, 7-11 March, 2004.

[18] Dimofte, F., Sawicki, J. T., Lambrulescu, M. I., Handschuh, R. F. and Davis, M. J. L., "Fluid Film
Bearing for Heavy Loaded Applications," Proc. of Third International Symposium on Stability Control of Rotating Machinery (ISCORMA-3), J. T. Sawicki and A. Muszynska, eds., 19-23 September, Cleveland, Ohio, USA, 2005, 182-191.

[19] Ene, N. M., Dimofte, F. and Keith, T. G. (Jr), “An Analysis of the Dynamic Regime of Hydrodynamic Wave Journal Bearings," Proc. of Third International Symposium on Stability Control of Rotating Machinery (ISCORMA-3), J. T. Sawicki and A. Muszynska, eds., 19-23 September, Cleveland, Ohio, USA, 2005, 270-278.

[20] Matsuda, K., Kijimoto, S. and Kanemitsu, Y., "Stability Optimized Clearance Configuration of Fluid Film Bearings," ASME Journal of Tribology, 129, 2007, 106-111.

[21] Reinhardt, E. and Lund, J. W., "The Influence of Fluid Inertia on Dynamic Properties of Journal Bearings," ASME Journal of Lubrication Technology, 97, 1975, 159-167.

[22] Gautam, S. S. and Ghosh, M. K., "An Approach to Calculate Leakage Flow, Stiffness and Damping of Annular Seals in Turbulent Flow Using Lubrication Theory, Part-I: Analysis," Tribology Online, 2, 4, 2007, 93-98.

[23] Launder, B. E. and Leschziner, M. A., "Flow in Finite-Width Thrust Bearings Including Inertial Effects, II- Turbulent Flow," ASME Journal of Lubrication Technology, 100, 1978, 339-345.

[24] Marquette, C. R., Childs,D. and San Andres, L. A., "Eccentricity Effects on the Rotor Dynamic Coefficients of Plain Annular Seals," ASME Journal of Tribology, 119, 1997, 443-44. 